\title{
agriculture
}

ISSN 2077-0472

www.mdpi.com/journal/agriculture

Article

\section{Small Ruminant Production System Efficiency under Abu-Dhabi, United Arab Emirates Arid Land Conditions}

\section{Eihab Fathelrahman ${ }^{1, *}$, Sherin Sherif ${ }^{2}$ and Dana L. K. Hoag ${ }^{3}$}

1 Department of Agribusiness and Consumer Sciences, College of Food and Agriculture, United Arab Emirates University, P.O. Box 15551, Al Ain, United Arab Emirates

2 Economics and Agribusiness Department, Faculty of Agriculture, Alexandria University, El-Shatby, P.O. Box 21545, Alexandria, Egypt; E-Mail: sherin.sherif@alexu.edu.eg

3 Department of Agriculture and Natural Resource Economics, College of Agriculture, Colorado State University, B330 Clark Building, Fort Collins, CO 80523, USA;

E-Mail: dana.hoag@colostate.edu

* Author to whom correspondence should be addressed; E-Mail: eihab.fathelrahman@uaeu.ac.ae; Tel.: +971-3-713-4589.

External Editor: Milan Shipka

Received: 27 August 2014; in revised form: 12 November 2014 / Accepted: 20 November 2014 / Published: 9 December 2014

\begin{abstract}
Sheep and goat production systems in the United Arab Emirates (UAE) operate under scarce natural resource constraints. A cross-sectional survey that covered 661 mixed farms, including major sheep and goat production, was conducted in the three regions of Abu Dhabi Emirate (Al-Ain, Western Region and Abu Dhabi city) during 2012. A Cobb-Douglas, double-logarithmic stochastic frontier production function and maximum likelihood estimation were applied to estimate important economic derivatives and the associated risk of small ruminant production in this arid area. The highest impact of an input on the output level was found to be labor for raising sheep and alfalfa grass for raising goats. Both labor and alfalfa variables were found to be overutilized for sheep and goat production, respectively. Overall, the results indicate that average technical efficiency is 0.62 for raising sheep and only 0.34 for raising goats in the study area. Technical efficiency analysis included measuring the frequency of farms at each level of estimated technical efficiency in the range between zero and one. Zero for the technical efficiency coefficient indicates a lack of technical efficiency in resource use. The results of this study indicated that only $1 \%$ of the sheep farms show a technical efficiency coefficient of 0.25 or less; the same can be said for
\end{abstract}


$41 \%$ of goat producers. However, these technical efficiencies were found to be more than 0.75 for $12 \%$ and $5 \%$ of the sheep and goat farms, respectively. Overall, goat farming in the UAE was found to be less efficient than sheep production. The results also indicated that flock size and type of breed were the most influential factors relative to other factors, and both show a positive relationship with technical efficiency. Other than flock size, factors, such as owners' years of experience and management practices, were found to be more influential on goat farming system efficiency relative to sheep farming.

Keywords: sheep and goats; arid land; technical efficiency; uncertainty; allocative efficiency; stochastic frontier; maximum likelihood; farm system intensity; food security

\section{Introduction}

The Food and Agriculture Organization [1] estimates that sheep and goat stocks in the United Arab Emirates increased from 52 thousand in 1960 to 1.5 million in 2010 for sheep and from 125 thousand in 1960 to 2 million in 2010 for goats (Figure 1). Meanwhile, the United Arab Emirates (UAE) imports more than $82 \%$ of its overall meat needs. Imports of mutton and goat meat represents $44 \%$ of the total supply in the country, leaving $56 \%$ of consumption satisfied from local production in 2009 . Red-meat production, consumption, prices and trade in the UAE are currently issues of high importance to the food security policy makers in the UAE government. The UAE imports red meat from Australia, New Zealand, India, Pakistan and other countries to fill an increasing demand gap due to increasing per-capita national income, which has led, in turn, to increasing consumption and demand for red meat.

Figure 1. Number of sheep and goat stock in the United Arab Emirates 1960-2010.

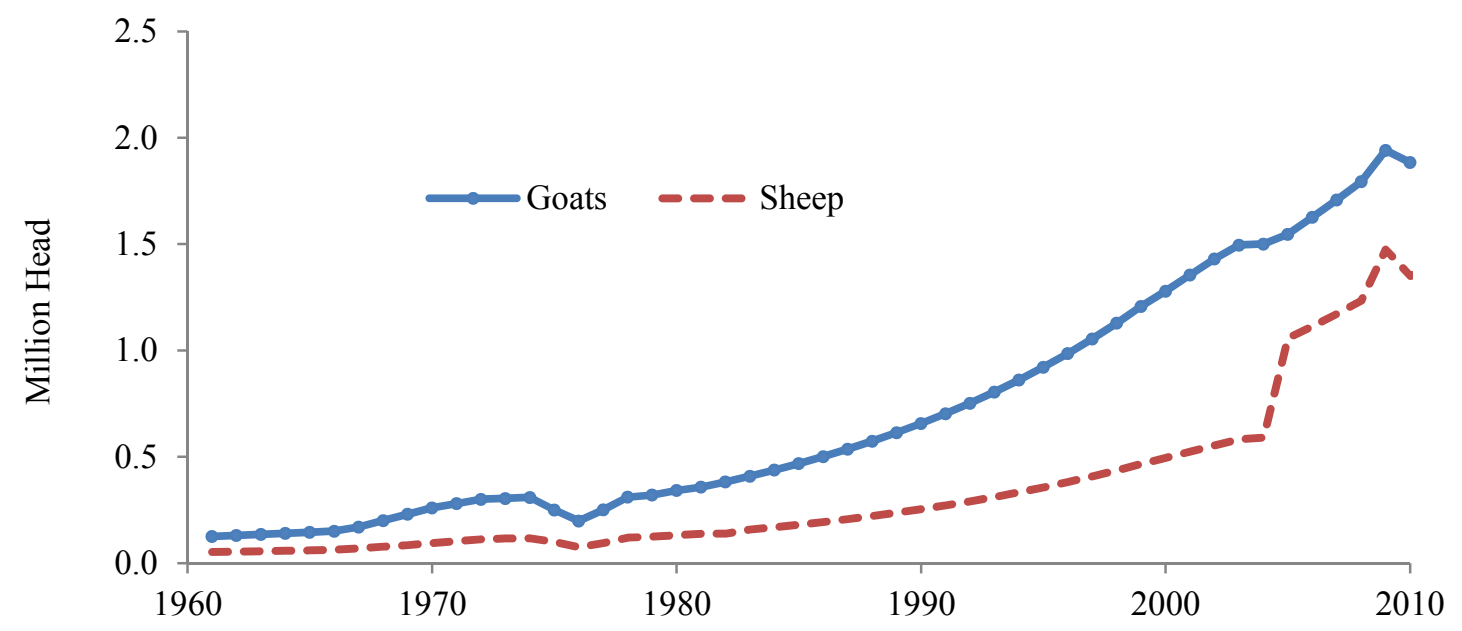

Source: Food and Agriculture Organization (FAO), 2013 [1]. 
Furthermore, similar to many other countries, the UAE has witnessed an increasing global and domestic emphasis on some important meat production and consumption attributes, such as meat products' quality and safety, in addition to environmental concerns. The UAE possesses relatively limited agricultural resources due to being in a typical arid region. With such limited agricultural resources, agricultural policies ought to address such issues as food security along with issues relevant to resource conservation. The current use of such scarce resources may lead to either economic overutilization or underutilization with possibilities of irreversible consequences. The UAE policy makers are working towards initiating and acquiring an accurate and comprehensive information system and building technical, economic and risk indicators to help producers of the red meat subsector. The UAE's Ministry of Environment and Water (MOEW) [2] is in the process of building a database for input use in the country's livestock sector.

The Arab Organization for Agricultural Development (AOAD) [3] showed that the United Arab Emirates self-sufficiency ratio (SSR) of red meat declined in the last four decades from $83.25 \%$ in 1982 to less than $2 \%$ in 2011. Increased mutton and goat meat production and productivity (meat produced per head) in the UAE play a vital role in reducing the self-sufficiency gap and stabilizing output prices.

The following section includes a review of studies that have addressed the technical, allocative and/or stochastic efficiency of sheep and goats. This section also summarizes studies that address policy options in response to reduced inefficiency, such as sheep and goat production system intensification. Zaibet et al. [4] investigated goat production impacts on socio-economic performance and development in Oman. The study considered a goat production system in a hill-country farming community located in the interior region. The area included forty villages with an average of ten families in each village where goats are raised for rural households. The authors used a data envelopment analysis (DEA) approach. DEA is a mathematical programming methodology that provides a non-parametric measure of relative efficiency. Then, the authors used two-stage ordinary least squares (OLS) to determine the components of the technical efficiency. Their research found that non-farm income and feeding costs are influential variables. Meanwhile, variables, such as farm size, flock size and family labor, were found to be non-influential variables in predicting changes in technical efficiency.

Hadley [5] studied the patterns of technical efficiency and technical change at the farm level in England and Wales. The objective of this study was predicting the relative technical efficiency of individual farms and explaining the differences in efficiency levels between these farms. Data for this research were obtained from the Farm Business Survey published by Defra and the National Assembly for Wales for the period 1982-2002. Farm products included in the survey were cereal, dairy, sheep, beef, poultry, pigs, as well as mixed farm products. Hadley's study applied the stochastic frontier and inefficiency effects models. The analysis showed that farms of all types are efficient and largely operate close to the production frontier.

Pérez et al. [6] offered a technical note on the technical efficiency of meat sheep production in Spain. The authors surveyed 49 farms in Aragon, Spain, where 3.5 million lambs are fattened per year on about 8000 sheep farms. The authors estimated Cobb-Douglas frontier production functions to estimate technical efficiency. In this study, the authors considered feed costs, capital depreciation and labor costs as the explanatory variables. One would notice the sample in this study to be very small relative to the total farms in the country (49 farms out of 8000 farms, or $0.6 \%$ ). However, the study highlighted 
the importance of sheep production costs, including inputs cost, as well as the sheep product market seasonality.

Villano et al. [7] measured regional productivity differences in the Australian wool industry using a metafrontier approach. Explanatory variables, such as feed/pasture, health, marketing and labor, were considered to explore the technical efficiency in each of the four selected regions using stochastic frontier functions. The study found that technical efficiency differences between the four regions are due to environment and agricultural extension services that were provided to sheep and goat farm owners.

Suresh et al. [8] studied the returns and economic efficiency of sheep farming in the semi-arid region of Rajasthan, India, based on the collection of field data relying on a survey questionnaire from 107 sheep farmers who reside within 20 villages during March 2005. The authors used a stochastic frontier model to analyze such economic efficiency. The authors found overall average economic efficiency to be 75 percent. Furthermore, the authors noticed that more than two thirds of the farmers are witnessing economic efficiency in the range of 70-85 percent.

Shomo et al. [9] analyzed the sources of technical efficiency of sheep production systems in dry areas in Syria using the results of a survey carried out in 2002. They applied stochastic frontier and maximum likelihood estimation to find that technical efficiency in the sheep production in Syria ranges from 0.67 to 0.97 . The authors concluded that flock size is a key factor in determining technical efficiency. The authors also recommended that producers should be encouraged to shift from traditional systems to intensive systems to increase technical efficiency.

Furesi et al. [10] analyzed the technical efficiency in the sheep industry for producing sheep milk in Sardinia (Italy). This study collected panel data from 36 sheep firms that produce sheep milk during 2004 to 2009. A stochastic frontier approach was used by Furesi et al. to assess the possibility of technical improvements in productivity. Technical efficiency was found to be 0.933 in these farms. The study included both private and cooperative farms and found significant differences between the two groups ( 0.93 for private firms and 0.88 for cooperative firms).

Economides [11] defined the sheep and goat intensive system to be the system that involves confinement of the flock with only limited grazing, for the goal of producing heavier lambs and kids. Such a system requires rationing of feed that utilizes available forage effectively, heavier use of appropriate (to the species and age of the animal) concentrates, a high level of veterinary care, better sheltering and feeding facilities and use of an automated system for handling inputs, animals and animals' products. However, such a system requires trained labor and increased management skills. Otherwise, investment may lead to low returns and probably high economic losses. Furthermore, Economides' [11] study indicated that if an intensive system for sheep and goats is successful, several advantages would be gained. Efficient use of inputs, including feed, labor and veterinary medicine, a steady supply of meat production and higher quality of final products justifies the initial investment in such intensive or semi-intensive systems.

Kumar [12], Sultana et al. [13] and Abdelqader et al. [14] studied the potential impacts of adapting sheep and goats in semi-intensive and intensive systems in similar arid regions to the UAE arid land. Kumar [12] concludes that goat rearing in India is rewarding in both semi-intensive and intensive systems. Sultana et al. [13] found that semi-intensive feeding systems were found to be more efficient, testing native sheep species in Bangladesh. However, the authors found that the intensive system is more efficient using lamb survivability criteria. Meanwhile, Abdelgader [14], investigating the length of 
productive life (LPL) of Awassi and Najdi ewes species in intensive production systems in the northern part of the Arabian Peninsula, found that variation in such LPL is due to differences in breed, management practices and flock effects. Furthermore, the authors found that the Awassi ewe breed fits the intensive system more than the Najdi breed and can survive longer. These studies' findings showed the positive potential for increased technical efficiency of the intensive sheep and goat farming under an arid land environment.

Previous studies covered in this research all agreed about using the stochastic frontier production functions in order to enable discovering sources of technical and allocative inefficiency. The selection of variables to analyze sources of technical efficiency widely differs from one study to another, which indicates that no single set of variable fits all research problems. Our study selected a larger number of variables to analyze sources of technical inefficiency relative to the previous studies (i.e., flock size, owner's years of experience, animal breed, total operational cost, land size and costs of concentrates).

The objectives of this research are: (1) to obtain the baseline information on the existing mixed-animal farms; (2) to determine the production efficiency of input use and the corresponding price efficiency; (3) to estimate stochastic analysis parameters, including out of control random unknown parameters that account for technical inefficiency in the production functions; (4) to understand the sources of such technical inefficiency; and (5) to use research results to find and propose possible alternatives for decision makers to address technical inefficiency in the UAE sheep and goat subsector.

\section{Experimental Section}

Data was collected during 2012 through a comprehensive cross-sectional survey of the sheep and goat farms located in three regions in the UAE. These regions are Al-Ain, Abu-Dhabi and the Western Region of the Abu-Dhabi Emirate. These areas are the main sheep and goat producing areas in the country.

\subsection{Data}

A summary of the survey descriptive statistics for the 661 mixed farms is illustrated in Table 1 . The average number of animals in farms was found to be 122 heads per farm for sheep and 106 heads per farm for goats. Sheep farms were using about 8 tons of tons of Rhodes grass compared to about 14 tons for goats annually. Farms use 47 and 44 tons of alfalfa for sheep and goats, respectively, on an annual basis. Sheep and goat farms use wheat bran, barely, corn, wheat and protein concentrates to complete sheep and goat diets. No large differences in using labor or water were found between sheep and goats in the Abu-Dhabi Emirate. Table 1 in the results section also shows that almost all coefficients of variation (standard deviation/mean \%) for output and input variables exceeded 100\%, which indicates a large variability between the various farms included in the sample. Such variability may indicate the presence of a wide range of practices and methods when it comes to sheep and goat feeding and other resource management practices applied by farmers in the Abu-Dhabi Emirate. 
Table 1. Descriptive statistics of output and input variables for sheep and goat production in Abu-Dhabi Emirate. AED, Arab Emirates Dirham.

\begin{tabular}{|c|c|c|c|c|c|c|c|c|c|}
\hline & \multirow[b]{2}{*}{ Unit } & \multicolumn{4}{|c|}{ Sheep } & \multicolumn{4}{|c|}{ Goats } \\
\hline & & Average & Range & Standard Deviation & $\begin{array}{l}\text { Coefficient } \\
\text { of Variation }\end{array}$ & Average & Range & Standard Deviation & $\begin{array}{l}\text { Coefficient } \\
\text { of Variation }\end{array}$ \\
\hline Number & Animal & 122 & 2000 & 139 & $113 \%$ & 106 & 1000 & 106 & $100 \%$ \\
\hline \multicolumn{10}{|l|}{ Feed } \\
\hline Rhodes Grass & Ton & 8 & 219 & 26 & $306 \%$ & 14 & 3504 & 139 & $978 \%$ \\
\hline Alfalfa & Ton & 47 & 1095 & 61 & $130 \%$ & 44 & 1095 & 60 & $136 \%$ \\
\hline Wheat Bran & $\mathrm{Kg}$ & 12 & 132 & 19 & $158 \%$ & 9 & 121 & 14 & $153 \%$ \\
\hline Barely & $\mathrm{Kg}$ & 3 & 100 & 8 & $224 \%$ & 3 & 72 & 6 & $216 \%$ \\
\hline Corn & $\mathrm{Kg}$ & 0 & 45 & 2 & $1086 \%$ & 0 & 23 & 1 & $1197 \%$ \\
\hline Wheat & $\mathrm{Kg}$ & 5 & 142 & 14 & $299 \%$ & 3 & 89 & 9 & $282 \%$ \\
\hline Protein Concentrates & $\mathrm{Kg}$ & 8 & 189 & 18 & $227 \%$ & 6 & 83 & 12 & $198 \%$ \\
\hline Labor & $\begin{array}{c}\text { Thousand } \\
\text { AED }\end{array}$ & 9 & 66 & 8 & $94 \%$ & 8 & 149 & 10 & $122 \%$ \\
\hline Water & $\begin{array}{c}\text { Thousand } \\
\text { AED }\end{array}$ & 4 & 144 & 9 & $235 \%$ & 4 & 72 & 7 & $192 \%$ \\
\hline
\end{tabular}




\subsection{Methods}

A production functions methodology is used in this research to assess the economic efficiency of input use; namely, technical (production) and price (allocative) efficiency. The production function exhibits an engineering (physical) relationship between variable inputs, on the one hand, and the outputs that these inputs affect. Technical (production) efficiency is inherent in the definition of the production function. This function indicates the maximum amount of output obtainable from the utilization of a specific quantity of inputs given the existing technology level governing the input-output relationship. Alternatively, a specified set of inputs cannot be recombined to produce a larger output or a specific level of output cannot be produced with fewer inputs. The said input-output relationship is assumed to be known with certainty; i.e., the producers know the eventual outcome of the production process at the beginning of the production period. Since these relationships are neither fully known nor controllable, a distribution of yields would be associated with each input use level. This range of expected yields depends on the estimated variability of the predicted yield corresponding to the specified input use level. Moreover, inputs included in the production function are assumed to be homogeneous and prices of both inputs and outputs are presumably known with certainty (Chambers [15] and Fuss and Mundlak [16]). Allocative efficiency, on the other hand, refers to the combinations of inputs that maximize individual or social objectives. It is defined in terms of two conditions: necessary and sufficient. The first is met in the production process when estimating the production function. The second varies with the objectives of the individual producer. Like most of the economic literature under perfect knowledge, the individual producer's objective is assumed to be profit maximization. It is defined as profit maximization through equating the value of the marginal product of the variable input to its unit price (Griffin [17]).

The log-log Cobb-Douglas deterministic production function used in this paper takes the following mathematical form:

$$
Y=a x_{1}^{b 1} x_{2}^{b 2}
$$

where $Y$ is the level of output, the $X$ 's are the inputs and $\alpha$ and $\beta$ are the function's coefficients. The assumptions embodied in the function's estimation are: $x_{i} \geq 0$ and finite (nonnegative, real inputs); the function is finite, nonnegative, real and single-valued for all possible combinations of $X_{1}$ and $X_{2}$; is everywhere continuous and everywhere twice continuously differentiable; and is subject to the law of diminishing returns.

This production function can be converted for the purpose of linear regression by taking the log as follows:

$$
Y_{i}=\beta x_{i}+\left(v_{i}-u_{i}\right), i=1, \ldots \ldots \ldots . \mathrm{N}
$$

where:

$Y_{i}=$ is the logarithm of the production/output of the $i$-th farm

$\beta=$ vector of unknown coefficients

$v_{i}=$ random variables, which are assumed to be $\mathrm{N}\left(0, \sigma v^{2}\right)$, that is all $v_{i} \mathrm{~s}$ are independently and identically distributed normal random variables with zero mean and variance $\sigma v^{2}$.

$u_{\mathrm{i}}=$ non-negative random variables, which are assumed to account for technical inefficiency in production. 
These random variables are assumed to be $\left|\mathrm{N}\left(0, \sigma^{2} u^{2}\right)\right|$; that is, $u_{i} \mathrm{~s}$ are independently and identically distributed half-normal (i.e., its pdf is a truncated version on the normal distribution) random variables with zero mean and variance $\sigma u$ (based on Collei [18] and Aigner [19]).

The estimation of technical efficiency coefficients for sheep and goats requires that this function be estimated using a maximum likelihood process. Maximum likelihood estimates (MLEs), as proposed by Coelli et al. [19] and parameterized (based on Jondrow et al. [20]) by a log-likelihood function for the half-normal model, are as follow:

$$
\ln \mathrm{L}(y \mid \beta, \sigma, \lambda)=-\frac{1}{2} \ln \left\{\frac{\pi \sigma^{2}}{2}\right\}+\sum_{i=1}^{I} \ln \phi\left\{-\frac{\varepsilon_{i}}{\sigma}\right\}-\frac{1}{2 \sigma^{2}} \sum_{i=1}^{I} \varepsilon_{i}^{2}
$$

where:

$$
\begin{aligned}
& y=\text { vector of the log-output; } \\
& \sigma^{2}=\sigma v^{2}+\sigma u^{2} \\
& \lambda^{2}=\sigma v^{2} / \sigma u^{2} \geq 0 \\
& \varepsilon_{i}=v_{i}-u_{i}=\ln q_{i}-x_{i}^{\prime} \beta, \text { the composite error term; and }
\end{aligned}
$$

$\Phi(x)=$ cumulative distribution function (cdf) of the standard normal random variable evaluated at $x$.

Therefore, Coelli et al. [18] suggested that technical efficiency be calculated as follows:

$$
\mathrm{TE}_{i}=\frac{q_{i}}{\exp \left(x_{i}^{\prime} \beta+v_{i}\right)}=\frac{\exp \left(x_{i}^{\prime} \beta+v_{i}-u_{i}\right)}{\exp \left(x_{i}^{\prime} \beta+v_{i}\right)}=\exp \left(-u_{i}\right)
$$

where:

$q_{i}=$ observed output.

The following section summarizes the results obtained from applying technical efficiency (TE), described above.

\section{Results and Discussion}

Survey results also revealed that sheep and goat farms are $86 \%$ and $14 \%$ of all sheep and goat farms, respectively, in the Al-Ain Region, Abu-Dhabi area and the Western Region of the Abu Dhabi Emirate. The majority of sheep and goat farms (428 farms out of 661 sample farms) were in operation for 10 years or less. The typical sheep flock structure was dominated by ewes; whereas doe's dominated the goat flocks. The average value products (market price) for sheep and goats were AED 116 and AED 93 per head, respectively (USD $1=$ AED 3.675). Almost all farmers (99\%) claimed that the farm is carrying the right capacity. Fifty seven percent of the farmers claimed they supply adult animals with concentrates. Fifty one percent of the water needs for both sheep and goats were supplied through tanks, followed by the Al-Ain Distribution Company (29\%) and groundwater (20\%). Meanwhile, 70\% of the sheep and goat farmers reported that they seek veterinary services when animals get sick. The main three health control measures adopted in sheep/goat farms are vaccination (76\%), dipping (68\%) and dew arming (68\%). Whereas $94 \%$ of farmers reported that they do not do animal identification, the $6 \%$ who reported that they used identification claimed using the ear-tagging method. Fifty six percent of sheep/goat farmers reported culling of sheep and goats from flocks for health reasons. Seventy nine percent of farmers reported having shades for each group of animals, with more emphasis on the newly born $(61 \%)$. Sources of price information were $9 \%, 8 \%$ and $9 \%$ from other farms, the government and 
negotiations with buyers, respectively. The reported annual total production of sheep and goats by number were 7661 and 5845 animals, respectively, with coefficients of variation of $135 \%$ for sheep and $120 \%$ for goats. Ten percent of sheep/goat farmers reported meeting market demands, whereas $38 \%$ claimed they do not, and 52\% did not respond to that question (Sherif et al. [21]).

The results section of this study proceed to include descriptive statistics of the research variables, technical efficiency results, allocative efficiency results and the stochastic analysis results to explore and analyze factors that influence technical, allocative (price) and uncertainty in sheep and goat production in Abu-Dhabi Emirate, UAE.

This research paper expands on the Sherif [21] conference proceeding paper to include stochastic frontier analysis utilizing the approach proposed by Coelli et al. [18]. Using the stochastic frontier methodology has an advantage over the deterministic approach in that it enables estimation of the technical efficiency distribution, as well as the inclusion of technical inefficiency sources. The deterministic approach uses the average of estimated technical efficiency and allocative efficiency for the overall sample without revealing information about technical efficiency at the specific farm in the study's sample. However, the stochastic frontier approach estimates technical efficiency at each farm and further shows the distribution of technical efficiency across all of the sample farms. Another advantage of the frontier approach is that it enables the analysis to further analyze the sources (e.g., species, feed or labor) of inefficiency. Stochastic efficiency analysis considers the analysis of both known uncertainty due to technical inefficiency and unknown sources of uncertainty. The stochastic component of this research was carried out using FRONTIER, version 4.1 software prepared by Coelli [22], for the Center for Efficiency and Productivity Analysis (CEPA).

\subsection{Sheep Deterministic Model: Technical Efficiency}

The following is the production function specification for sheep in Abu-Dhabi Emirate:

$$
\begin{aligned}
& Y=-0.060+0.053 \text { Rhodes }+0.289 \text { Alfalfa }+0.122 \text { Wheat Bran }+0.039 \text { Barley }- \\
& 0.086 \text { Corn }+0.066 \text { Wheat }+0.121 \text { Protein Concentrate }+0.056 \text { Minerals }+0.075 \\
& \text { Vitamins }+0.388 \text { Labor }+0.128 \text { Water }+0.6616829
\end{aligned}
$$

Equation (5) displays the estimated log-log production function for sheep, where $Y$ is the number of sheep (head produced/day), Rhodes and alfalfa are measured in tons/day, and wheat bran, barley, corn, wheat, wheat concentrate, minerals and vitamins are all measured in kilograms/day; labor is measured in thousand hours/year, and water is measured as cost in AED/year. The model's $F$-ratio was 287.557 (model statistically significant), adjusted $R$-squared $=0.827$ (all of the estimated variables explain $82.7 \%$ of the variations in the level of output); and the significant variables in the above estimated equation at less than the $1 \%$ level are Rhodes, alfalfa, wheat bran, wheat, protein concentrate, labor and water. The Standardized beta coefficients showed that the most prominent variables in affecting the level of output are, respectively labor, alfalfa, protein concentrate, wheat bran, water, wheat and Rhodes (Sherif et al. [21]). 


\subsection{Sheep Deterministic Model: Allocative (Price) Efficiency}

The ratio of the marginal value product of input $X\left(\mathrm{MVP}_{x}\right)$ and input price of $x\left(\mathrm{P}_{x}\right)$ was calculated for each significant input to test the null hypothesis that it is equal to one. Table 2 shows the results obtained for all of the significant inputs in the estimated $\log$-log function where: $\mathrm{MVP}_{x}=$ marginal value product of the variable input $X, \mathrm{P}_{x}$ is the average unit price of the variable input $X$ and MVP $x$ is equal to $\left(\mathrm{E}_{X} \times \mathrm{P}_{y} \times(Y / X)\right)$; where: $\mathrm{EX}$ is elasticity of production of the variable input $X, \mathrm{P}_{Y}$ is the average output price in AED, $Y$ is the average level of output and $X$ is the average level of the variable input $X$. According to the marginal economic production theory; if $\mathrm{MVP}_{x} / \mathrm{P}_{x}<1$, input is overutilized; if $\mathrm{MVP} x / \mathrm{P}_{x}=1$, input is optimally utilized; and If $\mathrm{MVP}_{x} / \mathrm{P}_{x}>1$, input is underutilized (Hall [23]).

Table 2 summarizes the allocative efficiency results of the variable inputs used in the production of sheep. Water was not included, because it was calculated as a monetary value per year and not as a physical amount, due to lack of data on the physical amounts. The table shows that all of the prominent variable inputs are overutilized as their $\mathrm{MVP}_{x}$ compared to their corresponding prices, $\mathrm{P}_{x}$, are less than one. Moreover, an elasticity of production of Rhodes, for instance, of 0.053 means that if the input level increases by $100 \%$, output would increase by $5.3 \%$, and so on, for the remainder of the regression coefficients (Sherif et al. [21]).

\subsection{Goat Deterministic Model: Technical Efficiency}

The following is the production function specification for goats in Abu-Dhabi Emirate:

$$
\begin{aligned}
& Y=4.702+0.052 \text { Rhodes }+0.395 \text { Alfalfa }+0.280 \text { Wheat Bran }-0.012 \text { Barley }-0.223 \\
& \text { Corn }+0.196 \text { Wheat }+0.296 \text { Protein Concentrate }+0.021 \text { Minerals }+0.007 \text { Vitamins }- \\
& 0.366 \text { Labor }-0.193 \text { Water }+1.3333559
\end{aligned}
$$

Equation (6) displays the estimated log-log production function for goats, where $Y$ is the number of goats (head produced/day), and all of the variable inputs are defined and measured in the same units used in the estimation of the sheep production function. The model's $F$-ratio is 26.346 , adjusted $R$-squared $=0.297$; and the significant variables in the above estimated equation at less than the $1 \%$ level are alfalfa, wheat bran, wheat and protein concentrate. Labor and water, however, were highly significant at less than the $1 \%$ level, but with unexpected negative signs. This could be due to overutilization of these two inputs due to recruiting cheap expatriate labor. The standardized beta coefficients showed that the most prominent variables in affecting the level of goat output are, respectively, alfalfa, wheat bran, protein concentrate and wheat (Sherif et al. [21]). 
Table 2. Allocative efficiency of the significant inputs used in the production of sheep. MVP, marginal value product; AED, Arab Emirates Dirham.

\begin{tabular}{|c|c|c|c|c|c|c|c|c|}
\hline & & & Output Price & Average & Average & Marginal & Input & \\
\hline Input & Unit & Coefficient & $\left(\mathbf{P}_{Y}\right)$ & $(Y)$ & $(X)$ & $\begin{array}{l}\text { Value Product } \\
\text { (MVP) }\end{array}$ & $\begin{array}{c}\text { Market Price }\left(\mathbf{P}_{x}\right) \\
\text { (AED) }\end{array}$ & $\mathbf{M V P}_{x} / \mathbf{P}_{x}$ \\
\hline Rhodes & Ton & 0.053 & 116 & 122 & 8 & (MVP) & 400.9 & 0.23 \\
\hline Alfalfa & Ton & 0.289 & 116 & 122 & 47 & 87 & 322.6 & 0.27 \\
\hline Wheat Bran & $\mathrm{kg}$ & 0.122 & 116 & 122 & 4380 & 0.4 & 0.8 & 0.53 \\
\hline Wheat & $\mathrm{kg}$ & 0.066 & 116 & 122 & 1825 & 0.5 & 1 & 0.51 \\
\hline Protein Concentrate & $\mathrm{kg}$ & 0.121 & 116 & 122 & 2920 & 0.6 & 0.8 & 0.78 \\
\hline Labor & $1000 \mathrm{~h}$ & 0.388 & 116 & 122 & 2.9 & 1919.9 & 3400.0 & 0.56 \\
\hline
\end{tabular}




\subsection{Goat Deterministic Model: Allocative (Price) Efficiency}

Table 3 summarizes the allocative efficiency results of the variable inputs used in the production of goats. $\mathrm{MVP}_{x} / \mathrm{P}_{x}$ shows that alfalfa is over-utilized. However, all other inputs (wheat bran, wheat and protein concentrates) are underutilized.

Deterministic models for sheep and goats in the UAE, Abu-Dhabi, were used primarily to estimate overall technical efficiency and allocative efficiency and to serve in step to include the stochastic component analysis. The stochastic component includes both the random variable due to the unknown and the technical efficiency component, which is further investigated in the stochastic analysis section later. Deterministic models are the first step to narrow down the explanatory variables. Only significant variables from deterministic models are considered for the stochastic frontier.

Table 3. Allocative efficiency of inputs for goats. MVP, marginal value product.

\begin{tabular}{ccccccccc}
\hline Input & Unit & Coefficient & $\begin{array}{c}\text { Output } \\
\text { Price } \\
\left(\mathbf{P}_{Y}\right)\end{array}$ & $\begin{array}{c}\text { Average } \\
(\boldsymbol{Y})\end{array}$ & $\begin{array}{c}\text { Average } \\
(\boldsymbol{X})\end{array}$ & $\begin{array}{c}\text { Marginal } \\
\text { Value Product } \\
\left(\mathbf{M V P}_{\boldsymbol{x}}\right)\end{array}$ & $\begin{array}{c}\text { Input } \\
\text { Market Price } \\
\left(\mathbf{P}_{\boldsymbol{x}}\right)\end{array}$ & $\mathbf{M V P}_{\boldsymbol{x}} / \mathbf{P}_{\boldsymbol{x}}$ \\
\hline Alfalfa & Ton & 0.395 & 93 & 106 & 45 & 86.5 & 322.6 & 0.27 \\
$\begin{array}{c}\text { Wheat Bran } \\
\text { Wheat }\end{array}$ & $\mathrm{kg}$ & 0.280 & 93 & 106 & 3285 & 0.8 & 0.8 & 1.12 \\
$\begin{array}{c}\text { Protein } \\
\text { Concentrate }\end{array}$ & $\mathrm{kg}$ & 0.196 & 93 & 106 & 1095 & 1.8 & 1 & 1.76 \\
\hline
\end{tabular}

\subsection{Sheep Stochastic Frontier: Maximum Likelihood Estimates}

Table 4 summarizes the sheep stochastic frontier production function using maximum likelihood estimates. These results show the expected positive signs for all of the selected explanatory variables and that all of these variables are significant. These estimates indicate that all coefficients on explanatory variables are smaller than those of the deterministic model results. This is due to the fact that technical efficiency is now accounted for as its own variable, and the stochastic model also considers variability due to out of control conditions: stochastic variability (e.g., due to changes in climate). For example, MLEs show that increasing Rhodes by $1 \%$ causes the sheep number produced in the flock to increase by $0.02 \%$. The gamma coefficient indicates that variation in the composite error term that is due to the inefficiency component (equal to 0.56 ). In other words, for sheep in the UAE, $56 \%$ of the variation in the error term is due to inefficiency.

\subsection{Goats Stochastic Frontier: Maximum Likelihood Estimates}

Table 5 shows the results for the goats' stochastic frontier production function using the maximum likelihood estimates. Different from the sheep model's results, using wheat to feed the goats is found to be insignificant $(T$-value $=1.5)$. The goats' stochastic model results indicate that increasing alfalfa by $1 \%$ causes the number of goats produced in the flock to increase by $0.16 \%$. The gamma coefficient indicates that variation in the composite error term that is due to inefficiency component (equal to 0.97). In other words, for goats in the UAE, $97 \%$ of the variation in the error term is due to inefficiency. 
Table 4. Sheep maximum likelihood estimates: stochastic production frontier.

\begin{tabular}{ccccc}
\hline Variable & $\begin{array}{c}\text { Overall Model } \\
\text { Fitness }\end{array}$ & Coefficient & Standard Error & T-Ratio \\
\hline Constant & & 0.16 & 0.16 & 9.48 \\
Rhodes (ton) & & 0.02 & 0.02 & 3.43 \\
Alfalfa (ton) & & 0.03 & 0.03 & 17.55 \\
Wheat Bran (kg) & & 0.02 & 0.02 & 4.67 \\
Wheat (kg) & & 0.03 & 0.03 & 2.74 \\
Protein Concentrates (kg) & & 0.02 & 0.02 & 4.16 \\
Labor (1000 h) & & 0.04 & 0.04 & 19.14 \\
Sigma-squared & 0.56 & 0.13 & 0.13 & 6.93 \\
Gamma & 0.13 & 0.13 & 4.45 \\
\hline
\end{tabular}

Table 5. Goat maximum likelihood estimates: stochastic frontier production frontier.

\begin{tabular}{cccc}
\hline Variable & Coefficient & Standard Error & $\boldsymbol{T}$-Ratio \\
\hline Constant & 5.06 & 0.09 & 54.39 \\
Alfalfa & 0.16 & 0.03 & 5.62 \\
Wheat Bran & 0.07 & 0.03 & 2.04 \\
Wheat & 0.07 & 0.04 & 1.50 \\
Protein Concentrates & 0.09 & 0.03 & 2.65 \\
Gamma & 0.97 & & \\
\hline
\end{tabular}

\subsection{Comparison of Sheep and Goats Technical Efficiencies}

Table 6 below summarizes the sheep and goat technical efficiencies and descriptive statistics. Figure 1 below compares the histograms for the sheep and goat technical efficiencies. Overall, average technical efficiency was found to be 0.62 for sheep and only 0.34 for goats. These descriptive statistics show that sheep technical efficiency compared to goats' technical efficiency is double on average. Furthermore, the distribution of goats' technical efficiency is skewed to the left (low) compared to the sheep technical efficiency distribution, which is slightly skewed to the right (high) (Figure 2 and Figure 3). These results show that sheep's production technical efficiency is higher than goats' production technical efficiency overall.

Table 6. Descriptive statistics of technical efficiencies parameters for sheep and goats.

\begin{tabular}{ccc}
\hline Indicator & Sheep & Goats \\
\hline Mean & 0.62 & 0.34 \\
Median & 0.64 & 0.32 \\
Mode & 0.45 & 0.01 \\
Standard Deviation & 0.12 & 0.23 \\
Minimum & 0.15 & 0.00 \\
Maximum & 0.86 & 0.91 \\
Range (Maximum-Minimum) & 0.71 & 0.91 \\
Coefficient of Variation & $20 \%$ & $69 \%$ \\
\hline
\end{tabular}


Figure 2. Sheep technical efficiency distribution.
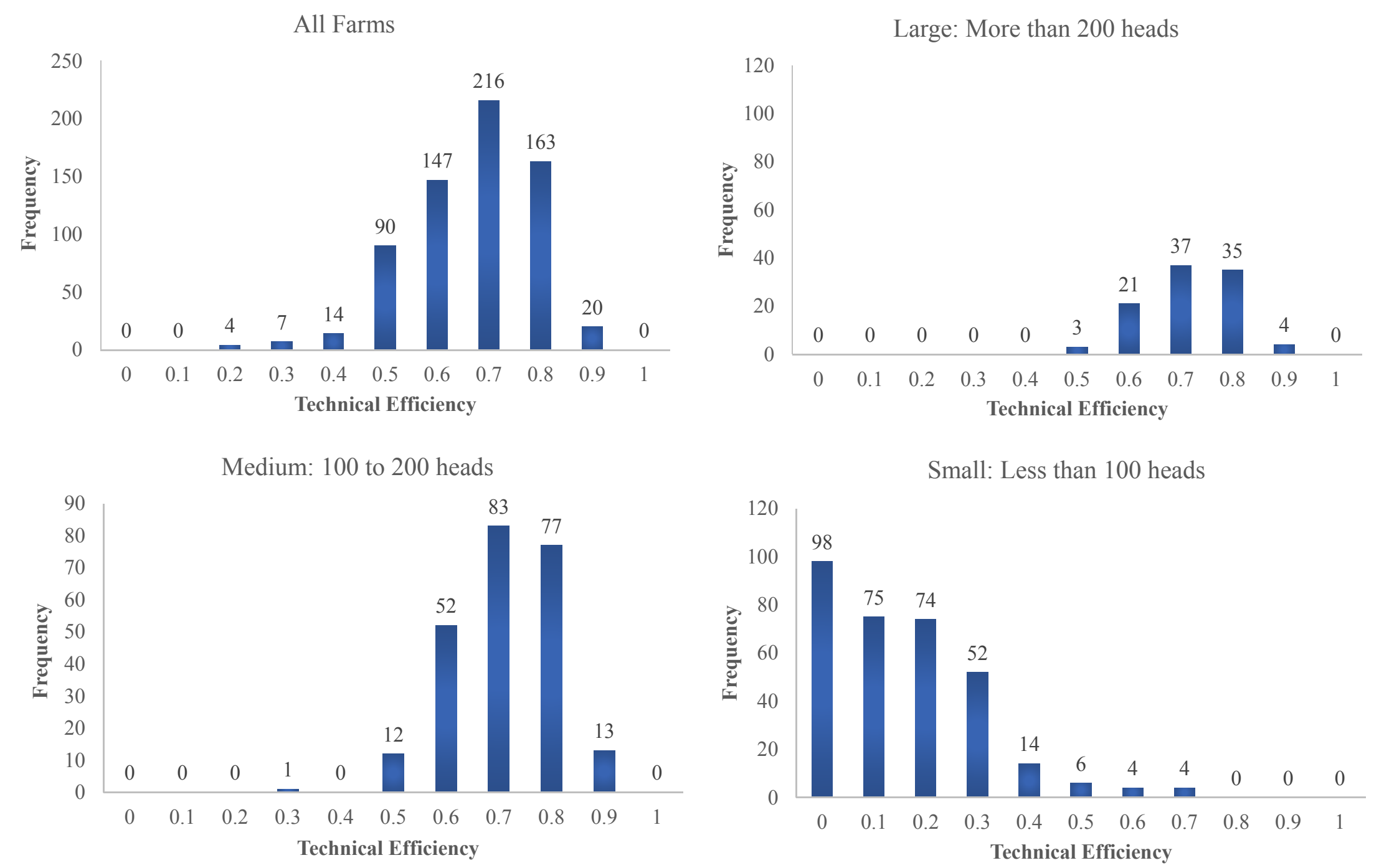
Figure 3. Goat technical efficiency distribution histograms.
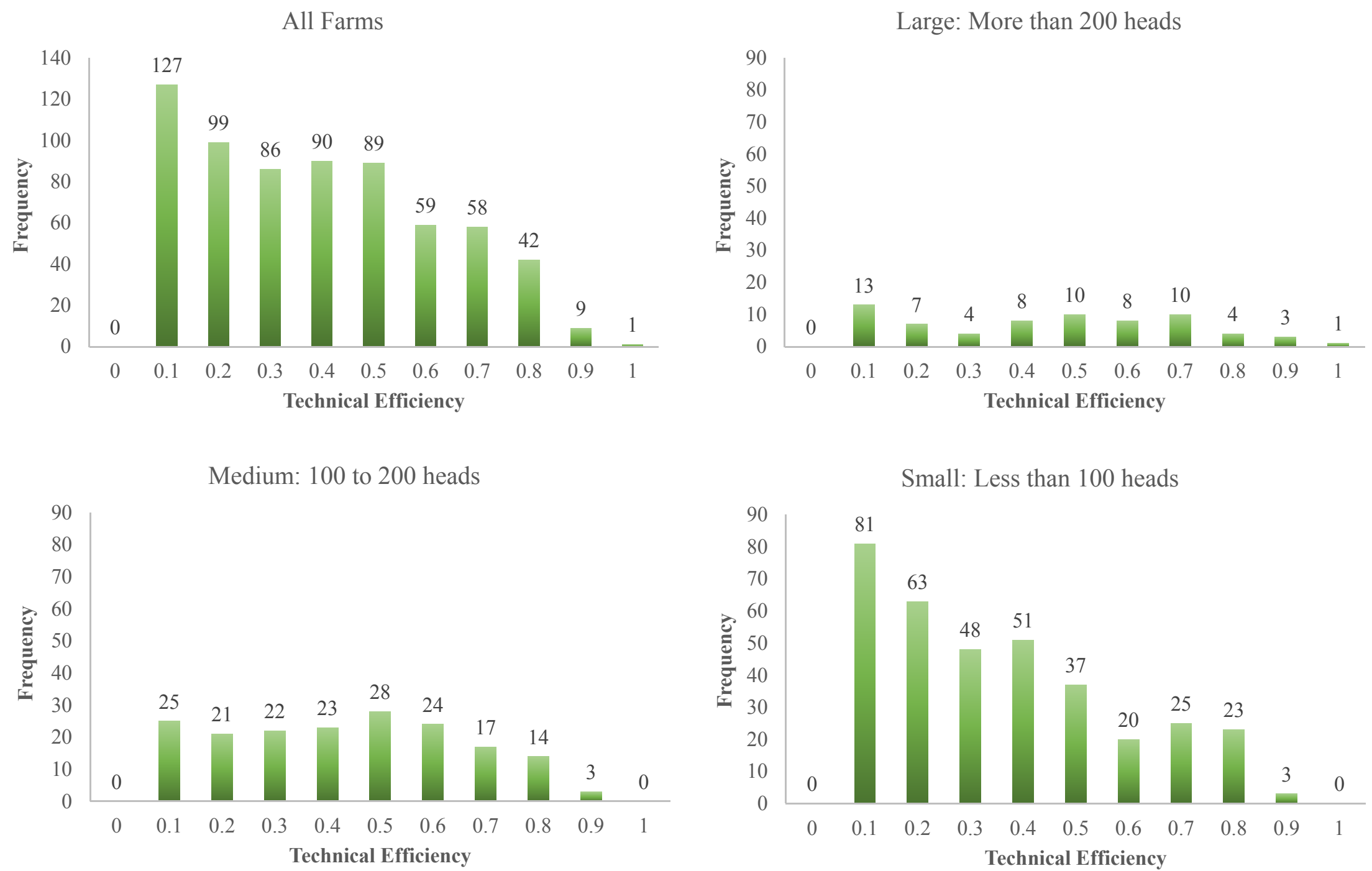
The technical efficiency distribution for the three sizes (large, more than 200 heads; medium, 100-200 heads; and small, less than 100 heads) of sheep is depicted in Figure 2, which shows that sheep technical efficiency is distributed, as expected, with higher technical efficiency for the large sized flocks. However, the distribution of goats' technical efficiency does not show similar results to the sheep distribution. For example, medium sized flocks (100-200 heads) of goats showed a higher technical efficiency level relative to the large sized flocks. This indicates that other than the flock size, the feeding system, owner years of experience and management practices may have more influence on goat production efficiency.

Descriptive statistics on goats showed that technical efficiency had a larger range (0.91) compared to (0.71) for sheep.

Table 7 further indicates that only nine of the sheep farms have a technical efficiency coefficient of 0.25 or less compared to 270 goats farms. On the other end, 80 sheep farms and only 33 goat farms showed more than a 0.75 technical efficiency coefficient. There is also a large difference between the number of sheep and goat farms within the other ranges of technical efficiency coefficients, with sheep farms showing a higher number of farms on both the range of 0.26 to 0.5 and 0.51 to 0.75 . In brief, sheep farms that achieve over a $50 \%$ technical efficiency coefficient or higher are $82 \%$ of the sample compared to only $27 \%$ of the goat farms.

Table 7. Number of sheep and goats farms at different levels of technical efficiency.

\begin{tabular}{ccccc}
\hline Level of Technical & \multicolumn{4}{c}{ Number of Farms } \\
\cline { 2 - 5 } Efficiency & Sheep & \% & Goats & \% \\
\hline 0.25 or Less & 9 & $1 \%$ & 270 & $41 \%$ \\
$0.26-0.5$ & 106 & $16 \%$ & 221 & $33 \%$ \\
$0.51-0.75$ & 466 & $70 \%$ & 137 & $21 \%$ \\
More Than 0.75 & 80 & $12 \%$ & 33 & $5 \%$ \\
\hline Total & 661 & $100 \%$ & 661 & $100 \%$ \\
\hline
\end{tabular}

\subsection{Distribution of Technical Efficiency by Herd Size}

Each of the sheep and goat farms in the sample is classified into three groups, large sized (more than 200 heads), medium (100-200 heads) and small (less than 100 heads). Technical efficiency distributions from the sheep histograms in Figure 2 are showing a pattern of increasing efficiency as the flock size increases. The relationship between flock size and technical efficiency does not follow a specific pattern of increased efficiency when the size of the flock increases. For example, small and medium sized flocks shows relatively higher technical efficiency compared to the same sizes of sheep flocks. These results indicate that flock size is one of the influential factors relative to other factors and has a positive relationship with technical efficiency in sheep production systems. Other than flock size, factors, such as owners' years of experience and management practices, are more influential on goats' production system efficiency. 


\subsection{Sources of Technical Inefficiency in Sheep and Goats}

Table 8 shows information on the investigation of the possible source of technical efficiency in sheep and goats in the Abu-Dhabi Emirate. These results indicate that flock size is the most influential factor relative to other factors and positively affecting technical efficiency. This is consistent with the concept of economies of size. Larger sized sheep and goat operations lead to economic benefits, as fixed costs are spread over a larger number of animals and increase the overall efficiency of the inputs used. Including the local breed in sheep was also found to be positively related to technical efficiency. However, this was not the case for goats, because no strong correlations were found between the difference in goat breed and or operation size, on one side, and the technical efficiency, on the other. Meanwhile, operating for more than 10 years, using concentrates in feeding ruminants and using vaccination to prevent disease spread variables were not found to be influential and positively correlated with increased technical efficiency.

All of the previous results above in relation to technical, allocative, stochastic efficiencies and sources of inefficiencies are used to draw conclusion, as well as to draw guidelines in a step to address policy options. Such conclusion and guidelines are included in the next section.

Table 8. Sources of technical efficiency in sheep and goats: correlation coefficients.

\begin{tabular}{ccc}
\hline Factor & Sheep & Goats \\
\hline Flock Size & 0.30 & 0.18 \\
Operating for More Than 10 year & -0.11 & 0.03 \\
Local Breed Is Included & 0.22 & -0.07 \\
Using Concentrated Feed & -0.001 & -0.01 \\
Using Vaccination & 0.03 & 0.03 \\
\hline
\end{tabular}

\section{Conclusions}

The current status of the United Arab Emirates' meat production subsector reveals that the deficiency in the meat group to satisfy local demand is on the rise. The red meat deficit is increasing annually, which, in turn, has led to deterioration in annual self-sufficiency ratios, with the deficit value growing annually by rates higher than those of the growth in the country's real Gross Domestic Product (GDP). The UAE government decided on adopting the resource-conservation type of policies. This study is focused on how to provide guidance to decision makers through identifying the current and ongoing use of scarce resources in the production of two important red meat sources; namely, sheep and goats. The venue was addressing the issue of input use economic efficiency. What increases the severity of the problem is the continuous rise in real per-capita incomes of the UAE citizens and a great number of expatriates that impose an ever-rising demand for red meat. Since the domestic production is insufficient, more importation is anticipated, implying a persistent and chronic decline in red meat self-sufficiency ratios.

In this study, marginal economic production theory, technical and allocative efficiency estimates and stochastic frontier methods were implemented to address input-use efficiency through the estimation of log-log production functions for sheep and goats separately. The study used the maximum likelihood estimate method to analyze stochastic efficiency and identify sources for such inefficiency in the UAE 
sheep and goat sector. The study concluded that the production of sheep and goats in the UAE, considered to be part of the UAE heritage, suffers from economic inefficiency of input use. Only one input, wheat bran, was found to be close to optimality in goat production. Other inputs were found to be either overutilized, like the case of sheep, or underutilized, like the case of goats. Moreover, the labor and water inputs, which were found to be positive and highly significant in impacting sheep production, were found to be significant and negatively impacting the level of goat production. Labor is commonly of the expatriate-low-wage type, and water is mostly subsidized by the government, both of which encourage UAE farm owners to overutilize. The estimated functions' coefficients represent the elasticities of the production of the said inputs. Through these coefficients, the responsiveness of outputs to percentage changes in input levels was assessed. The highest impact of an input on output level was labor in the case of sheep and alfalfa in the case of goats, both of which were found to be overutilized. Results indicated the inefficiency of the inputs utilized for sheep and goats; where all of the inputs used in sheep production were overutilized; whereas those used in goat production were underutilized in two cases and overutilized in one case, with only one input being close to economic-use optimality.

This study's results showed that, overall, average technical efficiency was found to be 0.62 for sheep and only 0.34 for goats. Technical efficiency coefficient distribution results indicate that about $82 \%$ of the sheep farms are achieving a 0.5 or more technical efficiency coefficient compared to only $27 \%$ of the goat farms. Results showed that $56 \%$ of the risk is due to technical inefficiencies' in sheep production. However, $97 \%$ of the risk can be attributed to technical inefficiencies in goat production. Furthermore, flock size is found to be the most influential factor relative to other factors and positively affecting technical efficiency. Sources of inefficiency are attributed to flock size and breed in sheep and only flock size in goats.

Policy makers in the UAE should consider revising the forage subsidy in response to alarming signs of the increasing rate of water scarcity. Such water scarcity is worsening due to past direct subsides distributed to small and large ruminant producers in the country. With the ongoing trend of the UAE government on subsidy reduction for inputs for sheep and goat producers, it is expected that farmers will further reduce the inputs used for animal production in response to such expected policy changes. This research identified the overall low levels of technical efficiency, especially on the goat production subsector, and concluded that flock size and breed of sheep are the most influential factors affecting technical efficiency.

In response to the low technical, allocative efficiencies, lack of water for pasture and high level of uncertainty livestock, the sector's policy makers in the UAE may consider several actions, including redirection of subsidies to the support of semi-intensive or intensive sheep and goat production programs, one the one hand. For producers, on the other hand, it is recommended to consider semi-intensive and intensive systems for small ruminant feeding, housing, healthcare and flock management in the UAE as a management option to address sheep and goat production systems' low technical efficiency, low allocative efficiency and high uncertainty. Such intensive sheep and goat systems are necessary to optimize resource use and guarantee sustainable future production. 


\section{Acknowledgements}

This paper was part of the Research Project No. 1440-06-02-10. The authors are indebted to the UAE University's Research Affairs Department and the Abu Dhabi Food Control Authority (ADFCA) for co-funding this project. Gratitude is extended to ADFCA for providing all of the needed logistics for field surveying of the farms. Acknowledgement is extended to Salih Al-Shorepy for his contribution on reviewing earlier versions of this manuscript and providing useful insights on the characteristics of small ruminant intensive systems.

\section{Author Contributions}

Eihab Fathelrahman designed the Maximum Likelihood Estimation (MLE) models performed the uncertainty analyses. Sherin Sherif designed and carried out the survey data collection from Abu-Dhabi Emirate regions' farms. He also designed and completed the technical and allocative efficiency analyses and verified the MLE process. Fathelrahman and Sherif contributed equally towards writing several versions of the manuscript. Dana Hoag completed the review of final manuscript document and validated the approach used in this article.

\section{Conflicts of Interest}

The authors declare no conflict of interest.

\section{References}

1. Food and Agriculture Organization of the United Nations Statistics Division (FAOSTAT). Available online: http://faostat3.fao.org/download/Q/QL/E (accessed on 15 September 2013).

2. United Arab Emirates Ministry of Environment and Water (MOEW). Available online: http://www. moew.gov.ae/en/knowledge-and-statistics/statistics.aspx\#page=1 (accessed on 20 March 2013).

3. Arab Organization for Agricultural Development (AOAD). Arab Agricultural Statistics Yearbook. Available online: http://www.aoad.org/AASYXX.htm (accessed on 20 March 2013).

4. Zaibet, L.; Dharmapala, P.; Boughanmi, H.; Mahgoub, O.; Al-Marshudi, A. Social changes, economic performance and development: The case of goat production in Oman. Small Rumin. Res. 2004, 54, 131-140.

5. Hadley, D. Patterns in technical efficiency and technical change at the farm-level in England and Wales, 1982-2002. J. Agric. Econ. 2006, 57, 81-100.

6. Pérez, J.; Gil, J.; Sierra, I. Technical efficiency of meat sheep production systems in Spain. Small Rumin. Res. 2007, 69, 237-241.

7. Villano, R.A.; Fleming, E.M.; Fleming, P. Measuring regional productivity differences in the Australian wool industry: A Metafrontier approach. In Proceedings of the AARES 52nd Annual Conference; Australian Agricultural \& Resource Economics Society (AARES): Canberra, Australia, 2008.

8. Suresh, A.; Gupta, D.; Mann, J. Returns and economic efficiency of sheep farming in semi-arid regions: A study in Rajasthan. Agric. Econ. Res. Rev. 2008, 21, 227-234. 
9. Shomo, F.; Ahmed, M.; Shideed, K.; Aw-Hassan, A.; Erkan, O. Sources of technical efficiency of sheep production systems in dry areas in Syria. Small Rumin. Res. 2010, 91, 160-169.

10. Furesi, R.; Madau, F.A.; Pulina, P. Technical efficiency in the sheep dairy industry: An application on the Sardinian (Italy) sector. Agric. Food Econ. 2013, 1, 1-11.

11. Economides, S. Intensive Sheep Production in the Near East. In FAO Animal Production and Health Paper No. 40; Food \& Agriculture Organization: Rome, Itay, 1983.

12. Kumar, S. Commercial goat farming in India: An emerging agri-business opportunity. Agric. Econ. Res. Rev. 2007, 20, 503-520.

13. Sultana, N.; Hasan, N.; Erhaduzzaman, M.; Talukdar, M.A.I.; Iqbai, A. Effect of intensive and semi-intensive feeding system on production and reproductive performance of native sheep. J. Sci. Res. 2011, 3, 693-698.

14. Abdelqader, A.; Yacoub, A.A.; Gauly, M. Factors influencing productive longevity of Awassi and Najdi ewes in intensive production systems at arid regions. Small Rumin. Res. 2012, 104, 37-44.

15. Chambers, R.G. Applied Production Analysis: A Dual Approach; Cambridge University Press: Melborne, Australia, 1988.

16. Fuss, M.; McFadden, D.; Mundlak, Y. A survey of functional forms in the economic analysis of production. In Production Economics: A Dual Approach to Theory and Applications; Elsevier North-Holland: Amsterdam, Netherlands, 1978; Chapter 4.

17. Griffin, R.C.; Montgomery, J.M.; Rister, M.E. Selecting functional form in production function analysis. West. J. Agric. Econ. 1987, 12, 216-227.

18. Coelli, T.J.; Rao, D.S.P.; O’Donnell, C.J.; Battese, G.E. An Introduction to Efficiency and Productivity Analysis; Springer: Queensland, Australia, 2005.

19. Aigner, D.; Lovell, C.A.; Schmidt, P. Formulation and estimation of stochastic frontier production function models. J. Econom. 1977, 6, 21-37.

20. Jondrow, J.; Knox Lovell, C.; Materov, I.S.; Schmidt, P. On the estimation of technical inefficiency in the stochastic frontier production function model. J. Econom. 1982, 19, 233-238.

21. Sherif, S.; Al-Shorepy, S.; Al-Juboori, A.; Fathelrahman, E. Sustainability of sheep and goat production systems under United Arab Emirates aridland constraints. APCBEE Procedia 2014, 8, 236-241.

22. Coelli, T.J. A Guide to FRONTIER Version 4.1: A Computer Program for Stochastic Frontier Production and Cost Function Estimation; Center for Efficiency and Productivity Analysis (CEPA) Working papers; The University of Queensland: Queensland, Australia, 1996.

23. Hall, H.H. Choosing an Empirical Production Function: Theory, Nonnested Hypotheses, Costs of Specifications. In Agricultural Economics Research Report No. 59; University of Kentucky, Department of Agricultural Economics: Lexington, KY, USA, 1998.

(C) 2014 by the authors; licensee MDPI, Basel, Switzerland. This article is an open access article distributed under the terms and conditions of the Creative Commons Attribution license (http://creativecommons.org/licenses/by/4.0/). 